\title{
TRANSIENT LUNG CONSOLIDATION IN ASTHMATIC CHILDREN * WITH REFERENCE TO EOSINOPHILIA
}

\author{
BY \\ BERTIL SÖDERLING
}

(From the Paediatric Clinic of the Caroline Institute at Norrtull Hospital

Stockholm. Director : Docent C. Gyllensvärd.)

The discovery of lung consolidation appearing in rapidly passing attacks in allergic diseases renders possible an important contribution to the group of ' unspecific lung changes,' and an explanation is thereby afforded of a number of pathological lung conditions, the symptoms of which could not be reconciled with those of previously known complaints. Although Löffler of Switzerland has the honour of being the first to describe cases of this type-called by him 'Flüchtige Succedaninfiltrate mit Eosinofili' $(1932,1934)$-it appears to the present writer that the most significant contribution has been made by Engel, of Shanghai, who in a publication in 1935 reports as follows :

During the months of May and June a very large percentage of the inhabitants of China are attacked by a peculiar bronchitis which in everyday life is called 'privet cough.' Privet is the name of a species of ligustrum which flowers at the time mentioned. The complaint manifests itself in a cough of moderate intensity, with a scanty, canary-yellow sputum with a metallic taste, which is stated to contain a few leucocytes and microbes. As only inappreciable discomfort accompanies the complaint, which is thought to be associated with the flowering of the above-mentioned plant, a doctor is not consulted.

The complaint has not therefore been investigated to any extent, and accounts of it had probably not been published until Engel did so ; and he would certainly not have had any reason to concern himself with it if he had not been affected by it himself. On this account he had reason to devote greater attention to the complaint and twice made $\mathrm{x}$-ray photographs of his lungs. On both occasions they revealed a massive pulmonary consolidation which completely cleared up after one day, and on another occasion after six days. At the same time the blood showed an eosinophilia between 20 and 25 per cent. with an otherwise normal blood picture. The sedimentation rate was $10 \mathrm{~mm}$. He was completely fit for work. In another person Engel found approximately the same morbid picture with similar transient lung changes. This person, however, showed moderate blood eosinophilia (6 per cent.); eosinophilia in the sputum is not mentioned.

* Other suggested names for the condition are Flüchtige Succedaninfiltrate mit Eosinofili (Löffler) and Oedema allergicum pulm. (Engel). 
The confinement to a particular season, the transience and the eosinophilia suggested the allergic genesis of the complaint, and Engel suspected the allergen to be material from the flowering ligustrum plant (cf. similarity with ordinary hay-fever). Engel has scrutinized Löffler's cases with regard to the time of their appearance, and finds that they all occurred during June and July, which, in association with other allergic symptoms, arouses suspicions of an analogous etiology.

Engel conceives the lung changes as a Quincke's oedema in the lung, and proposes the designation 'oedema allergicum pulmonis' for the disease. Therapeutically - if any remedy at all be required-calcium lactate in a dose of 3 grammes per diem is recommended.

Löffler has summarized the symptomatology of the disease as follows (1934) :

Weiche, gleichmässige, zum Teil aber auch fleckig-streifige Schatten beliebiger Lokalisation, manchmal rasch verschwindend und an anderer Stelle wieden auftretend, gelegentlich in Mehrzahl vorhanden. Die Schatten verschwinden innerhalb von 8-14 Tagen. Charakteristisch ist das oligosymptomatologische klinische Bild. Der akustische Befund ist sehr gering : keine Dämpfung, selten Knistern, Reiben. Leukocyten : 4-8000. Charakteristisch ist die Eosinophilie, die bis 66 per cent. steigen kann. Die Eosinophilie bietet einen Hinweis, auf anaphylaktoide Prozesse. Senkung etwas erhöht. Subjektive Beschwerden gering, etwas Husten, wenig Auswurf.

In Sweden Hansson (1934) and Eckerström (1936) have published contributions on the question. I discussed the problem in a paper in 1936, based on eleven cases of transient, probably allergic, lung consolidation in adults. I pointed out that when making the diagnosis of allergic lung consolidation too much significance should not be attached to an increased eosinophilia, which may be temporarily or entirely absent, but more to general allergic symptoms, such as asthma, asthmatic bronchitis, hypersensitivity reactions, and local symptoms, such as sputum-eosinophilia. Eosinophilia in the blood may be disguised, reduced or eliminated by the presence of the infection, with fever, which gave rise to the asthmatic bronchitis or the attack of asthma. Asthmatics fall ill with fever and have asthmatic attacks without an increase of eosinophils in the blood, in certain cases the eosinophilia again coming into evidence after the fever and the infection have subsided. Examples have been met in which the eosinophil count rises from zero on the day of admission to 20 per cent. after some days-but one type of child never shows a blood eosinophilia in spite of relatively long periods of observation. (Case 3 and the case described in connexion with it may be sufficient examples of this.) The difficulty of obtaining sputum specimens from children (a gastric lavage specimen would hardly be representative) has prevented the study of the strictly local eosinophilia (i.e. in the sputum) in these ' eosinophilanergic' cases. In one case of asthma without eosinophilia (case 3 below) a very definite but transient sputumeosinophilia was shown. In several other cases I have been able to prove that the eosinophilia in the blood does not run a parallel course with the local eosinophilia. The chief significance of an eosinophilia is probably a reaction 
against a protein which is foreign to the species, and at the present time the allergen must certainly be considered to be protein in nature. But other allergen substances (carbohydrates, for example) may exist, and nothing is known of their capacity to give rise to an eosinophilic blood picture. It is possible that different protein allergens may cause different degrees of eosinophilia.

I have already pointed out the 'unreliability' of eosinophilia in children in a paper in 1935, describing a number of less common pulmonary and pleural complications in asthmatic children. An account is there given of a group of five children with transient lung changes, which could not be interpreted as due to ordinary non-specific or specific pulmonary diseases, since the patients were afebrile and tuberculin negative. I did not venture at that time to describe these cases as of the same type as Löffler's on account of some differences in symptomatology. Thus four of my cases had symptoms of bronchitis, which Löffler's did not exhibit ; eosinophilia had not been demonstrated in all of them. Further, Löffler interpreted his cases as being due to some sort of abortive bronchopneumonia or 'Frühinfiltrat,' not emphasizing the possibility of an allergic genesis, and differing greatly from my conception of my own cases. Now, when experience in the subject has been considerably increased, I do not hesitate to include at least four of them $(1,3,4,5)$ as cases of ' transient lung consolidation in asthmatic bronchitis,' which I consider to have mainly the same basis-allergic-as the cases in adults described by Löffler and Engel, although they may have reacted to other allergens. How these allergic lung manifestations were brought about from a mechanical point of view is another problem. It is not unreasonable to suggest that the cause lies in a stagnation of secretion combined with bronchial spasm, resulting in collapse of the lung.

With regard to the nature of the allergen, it is of interest to mention that recently infected tuberculin-allergic patients may possibly react with transient lung changes, which are thus not true bacillary infiltrations but tuberculinallergic lung manifestations of the same class as non-specific transient lung consolidations. This process is analogous to that in asthma cases with bacterial allergy. Leitner's (1936) cases of transient lung infiltrations in a group of tuberculous sanatorium patients may perhaps be considered in this light. The occurrence of genuine tuberculous bacillary infiltrations of such transience must otherwise be regarded as a new discovery, though one for which Leitner has given no conclusive or even probable proof.

\section{Case records}

Two of the cases described previously (1935) will be briefly recapitulated here in the light of modern possibilities of interpretation and widened experience.

Case 1. Lilian K., born 1930. (Case records : 606/33, 281/34.) Since 1932 the patient had been troubled with relapsing bronchitis, for which the medical practitioner had been consulted five times during the autumn of 1932 . At the first examination, in August, 1933, a typical asthmatic bronchial catarrh 
was diagnosed (emphysematous thorax, added sounds on auscultation and wheezing in the chest with prolonged expiration. Many sibilant and sonorous rhonchi and loose râles diffusely over both lungs). The tuberculin test was negative and the child was afebrile. Her tonsils were removed in September, 1933. There was no improvement in the bronchitic trouble subsequently. Between October 18 and October 22 a period of swinging fever occurred. She was admitted to the hospital on October 22. Except on the day of admission, she was completely afebrile ; on admission she exhibited signs of a pharyngitis and the findings in the lungs described above, which still manifested an asthmatic bronchitis. There was no definite dullness and no clinical signs of bronchopneumonia. The Mantoux tuberculin reaction was negative $(1 \mathrm{mgm}$. O.T.). She was now subjected to an x-ray examination for the first time (October 23), which gave the following result : in the right hilus a massive consolidation and in the upper posterior part of the right lower lobe a similar massive parenchymal shadow. The heart was displaced slightly to the right, the upper interlobar limit somewhat drawn down, but the position of the diaphragmatic arch was normal. Atelectasis was probably present. The patient was given an appointment for further x-ray examination on November 4, but neglected to come until later, and the next roentgen examination was made on December 27, 1933. It was then observed that the right-sided consolidation had disappeared, but that a left-sided hilar consolidation with a gland shadow had appeared instead. Outside, in the anterior-lateral parenchyma and centrally, there were streaky and reticular parenchymal shadows, wedgeshaped in the lateral view. At the time of the examination the patient was completely afebrile, but coughed and exhibited a moderate amount of added sounds in the lungs. During the first few months of 1934 the patient improved, and at times the bronchial catarrh entirely disappeared. She increased in weight and was still free from signs of fever or infection. X-ray examination on April 9, 1934, showed a quite surprising and considerable relapse on the right side, in that the hilar changes were more clearly pronounced and a wedgeshaped shadow between the lower and central lobes had appeared. Blood examination showed 10 per cent. eosinophils. The Mantoux reaction was negative ( $3 \mathrm{mgm}$. O.T.). (Gastric lavage specimen injected into guinea-pigs was negative.) Sedimentation rate $10 \mathrm{~mm}$. The girl continued to enjoy unusually good health and was without any noteworthy symptoms, and after a week (April 16) a fresh x-ray photograph was taken. The right-sided parenchymal shadow had disappeared, but a dense area the size of a farthing was now observed in the left lung at the level of the fourth rib. This had disappeared by April 30. Eosinophilia was then $2 \frac{1}{2}$ per cent. Sedimentation rate $3 \mathrm{~mm}$. The girl has subsequently enjoyed fairly good health, and x-ray pictures have revealed nothing of particular note. Since June, 1935, she has not been re-examined.

Case 2. Wiel H., born 1928. (Case record: 630/32.) During the autumn of 1932 she had repeated bronchial trouble. She was admitted for observation and examined by x-ray on December 27, 1932. A massive consolidation was found in the lower part of the upper lobe with a slight displacement of the heart to the left and a retracted interlobar furrow. The girl was quite afebrile and her general condition unaffected. The Mantoux reaction was negative $(5 \mathrm{mgm}$.). There were signs of emphysema in the lungs with râles and a slight dullness over the central posterior lateral part of the left lung. The patient was examined by x-rays on February 13,1933, and the consolidation referred to had then disappeared entirely. The girl's bronchitis developed later into asthmatic bronchitis with typical attacks. No estimation of eosinophilia was made at the time. 
Unfortunately it has only been possible to bring the two cases described into the discussion as an afterthought, as at the time when the patients were under treatment we did not know of or consider the possibility of allergic lung consolidation. From a differential diagnostic point of view bronchopneumonia may possibly be considered in the first case. In that case it gave no physical signs, which is somewhat remarkable in view of its extent. Nor is the swinging fever for four days typical, and the x-ray picture is hardly compatible with a pneumonia, which must remain an unlikely diagnosis. Finally, the later remarkable changes between left- and right-sided shadows observed by x-rays, without clinically corresponding findings, certainly cannot be accounted for by bronchopneumonia. The patient's asthma and eosinophilia of 10 per cent. are certain signs of her allergic disposition.

The other patient's relapsing bronchitis and emphysematous thorax excited suspicions of allergic causes as early as the autumn of 1932, and these were verified later. Her rapidly disappearing lung consolidation, which does not prevent her from being up and about, her afebrile and unaffected general condition, hardly allow of any other explanation than allergic lung consolidation.

As far as I can find, these two patients are the first cases which have been described in the literature of Löffler-Engel's disease in children, or at least they may, with a high degree of probability, be suspected of belonging to that group. One case of allergic lung consolidations, which appears perfectly definite and which was diagnosed early and satisfactorily followed by $\mathrm{x}$-ray, is afforded by the following recently observed patient.

Case 3. A twelve-year-old girl, previously unknown to us, was referred to the hospital with a severe and typical attack of asthma. From the history it appears that the patient had, during the preceding six months, relapsing bronchitis of an asthmatic nature, but without attacks of asthma ; this was probably now followed by an infection of the air passages. She had her

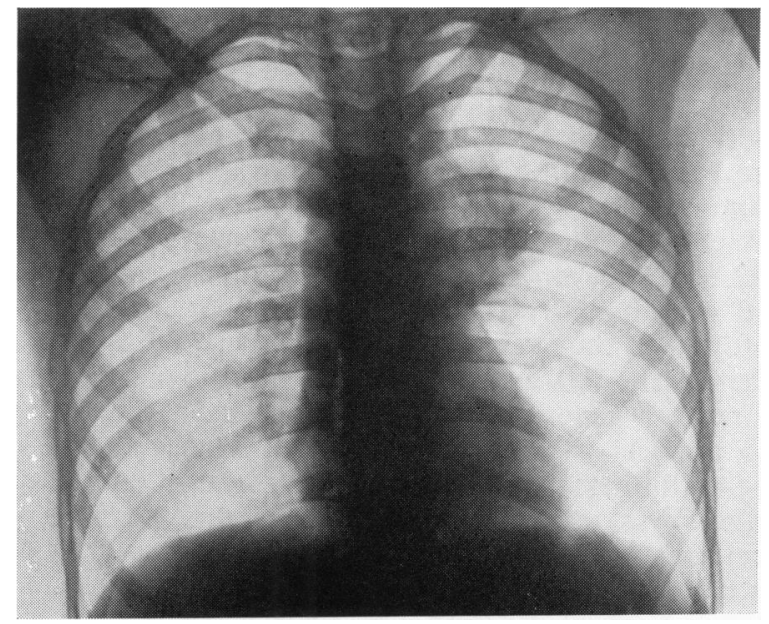

FIG. 1a.-February 26, 1938. 


\section{LUNG CONSOLIDATION IN ASTHMATIC CHILDREN}

tonsils removed in December, 1937, and was subsequently worse rather than better. The asthmatic attack we are now concerned with occurred on February 25, 1938, and she was nursed at the hospital from February 25 to March 19, 1938. The patient had a low pyrexia on admission, but her temperature soon fell to normal. The sedimentation rate was $25 \mathrm{~mm}$. on admission, and after fourteen days $11 \mathrm{~mm}$. After the asthmatic attack had subsided the patient was entirely unaffected and without discomfort, apart from a certain expiratory dyspnoea.

LUNG FINDINGS : Pronounced bilateral emphysema, no absolute cardiac dullness. On February $25 / 26$ centrally above second and third left intercostal spaces there was a definite dullness and strikingly harsh inspiration with numerous harsh râles, which appeared to be very superficial, resembling

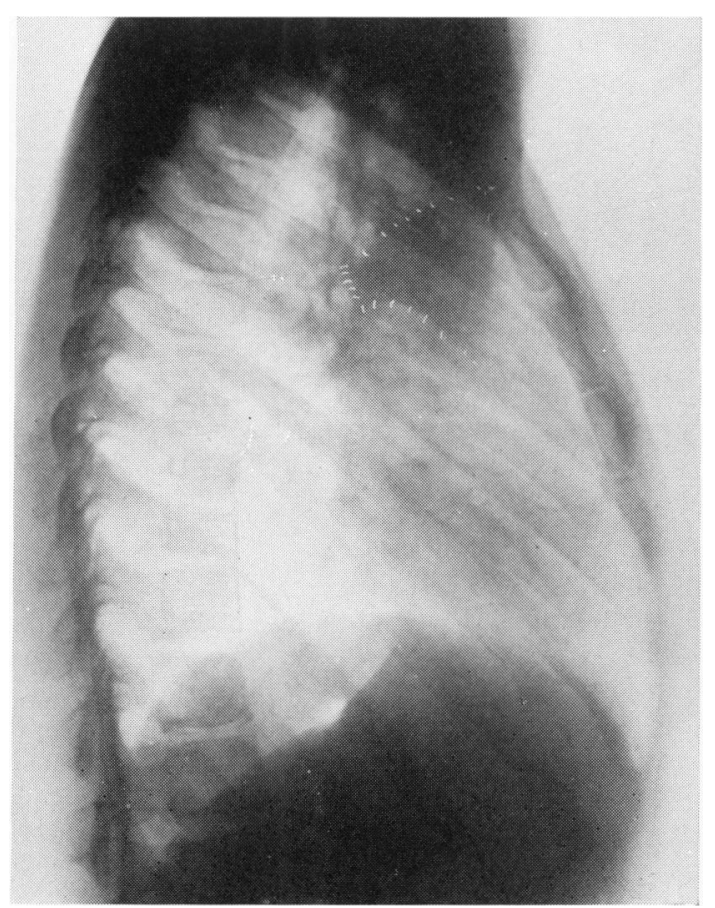

FIG. 1b.-February 26, 1938.

pleural sounds. There was no altered bronchophony. Elsewhere there were diffuse isolated sibilant rhonchi. X-ray examination on February 26 revealed a massive consolidation in the left lung, in the anterio-posterior view lying centrally outside the upper hilar area. In the lateral view the consolidation appears as a triangle with the base against the anterior thoracic wall (see fig. $1 a, 1 b$ ). On February 28 the physical change had disappeared, and x-ray examination revealed that the consolidation had also gone, but instead an induration of the central lobe of the right lung was observed (atelectasis) (see fig. $2 a, 2 b)$. On physical examination, there were scanty signs over the seat of the induration, slightly weakened respiratory sounds, and small harsh râles at the right base. On the following day (March 1) the induration of the central lobe had cleared up considerably, but was still observable (fig. 3). On the next day it had almost completely disappeared.

Adrenalin, given intramuscularly and by inhalation, had no definite effect 
on the consolidated areas. The patient received an adrenalin injection on admission, which, as appears from the above, did not prevent the lung changes.

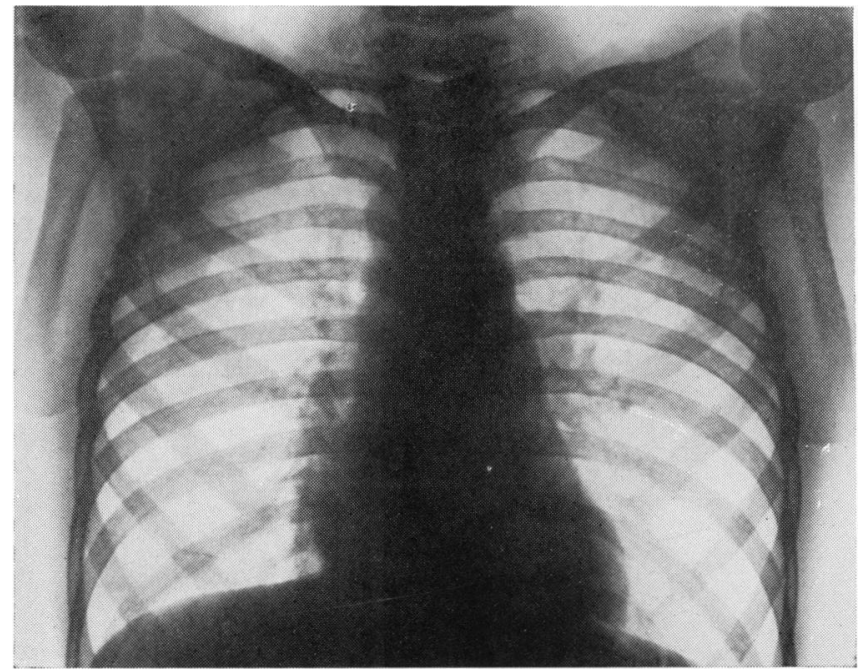

FIG. 2a.-February 28, 1938.

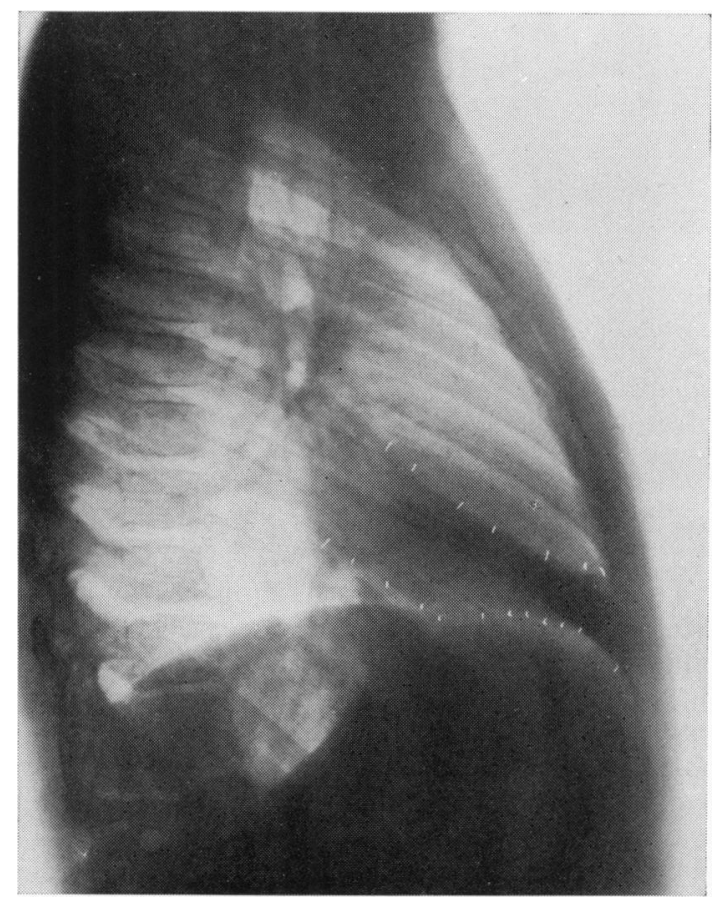

FIG. 2b.-February 28, 1938.

On March 1 the patient was made to inhale a spray of adrenalin solution $(1 / 1000)$, followed by $x$-ray examination after an hour or so. There was no appreciable difference in the $\mathrm{x}$-ray pictures. 


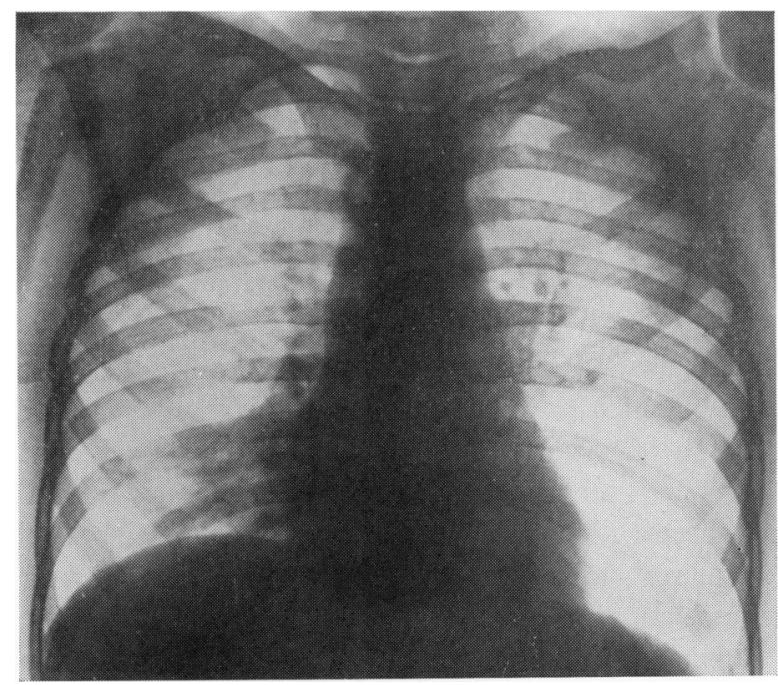

Fig. 3.-March 1, 1938.

Blood Picture :

White blood corpuscles

\begin{tabular}{|c|c|c|c|c|c|}
\hline \multirow{3}{*}{$\begin{array}{l}\text { Feb. } 28 \\
\text { March } 2\end{array}$} & \multicolumn{3}{|c|}{ White blood corpuscles } & \multicolumn{2}{|c|}{ Eosinophils } \\
\hline & $\cdots$ & 9,400 & c. $\mathrm{mm}$. & $3 \cdot 7$ & er cent. \\
\hline & .. & 14,300 & , & 4 & $"$ \\
\hline 4 & . & 7,600 & ", & $4 \cdot 3$ & ", \\
\hline , & . & 11,800 & , & $2 \cdot 3$ & , \\
\hline 12 & .. & 9,000 & , & 4 & , \\
\hline , 15 & . & 9,300 & ” & 3 & , \\
\hline
\end{tabular}

Qualitatively the picture was otherwise normal.

SPUTUM : Specimens obtained on March 3 and 4 showed numerous eosinophil cells on the first day, which had largely disappeared on the second day.

TUBERCULIN TEST : Mantoux $1 \mathrm{mgm}$. negative.

A discussion of the differential diagnosis in this case is hardly necessary. The allergic illness and extremely transient lung consolidations afford a clear diagnosis. As has been mentioned previously, it may be suspected that the asthmatic lung consolidations are conditioned by atelectasis, a fact which has been further emphasized by the lateral x-ray pictures (see figs. $1 b, 2 b$.) The absence of blood eosinophilia but the presence of a dominating number of eosinophil cells in the sputum is interesting. It should be observed that, during her three weeks in the hospital, the girl did not on any occasion exhibit a higher blood eosinophilia than 4 per cent.

With regard to the eosinophilia, the following case (case 2 in the 1935 paper) is analogous to the previous one.

Ulla-Brita, J., born 1929, has had since 1931 an almost continuous hacking cough, which is periodically accentuated, but unassociated with attacks of asthma. Owing to increased symptoms the patient sought medical advice, and proved to be tuberculin negative and afebrile ; she exhibited signs of a diffuse bronchitis, with slight emphysema and diffuse, bilateral sibilant rhonchi. $\mathrm{X}$-ray examination revealed a non-transient basal opacity (bronchiectasis with atelectasis ?). The condition reacted extremely well to potassium iodide. 
There was no increased blood eosinophilia. The diagnosis of ' asthmatic bronchitis ?' was made, and was verified some months later ; the patient was then admitted with a severe and typical attack of asthma, and subsequently had a relapse. She was treated in hospital for two months (partly for social reasons), when repeated eosinophilia determinations were made (at first twice a week). Apart from a single value of 8 per cent. after seven weeks at the hospital, no pathological increase in the number of eosinophil leucocytes could be established.

\section{Differential diagnosis}

Differential diagnosis does not afford many possibilities in cases of allergic lung consolidations which have been thoroughly examined. A diagnosis which is often resorted to is 'abortive pneumonia.' I consider that this diagnosis constitutes a lumber-room into which are thrown all sorts of indefinite and unspecific lung cases. In view of the extraordinarily typical and welldefined morbid picture afforded clinically by bronchopneumonia, it appears to me to be somewhat of a contradiction in terms when practically everything characteristic is absent. It would be better for the time being to reserve the diagnosis ' bronchopneumonia' for patients who have had fever for several days and are unfit for work, in which cases physical manifestations (inspection, percussion, auscultation) usually give the classical findings at once, sometimes later (e.g. central bronchopneumonia), and, if an x-ray examination has been made, it reveals a corresponding parenchymal consolidation ; in these cases, moreover, the history is generally characterized by acute onset, shivering, and stained sputum. (We must possibly make an exception here for anergic individuals.) If the case diverges from the clear and classical picture, it is necessary to examine more closely the history and laboratory findings, and to turn attention from the one particular organ. The proving of allergic lung consolidations implies increased resources of differential diagnosis, and it would probably be in better accord with sound medical common sense to make the diagnosis of allergic lung consolidations rather than inflammation of the lungs in the case of patients with allergic manifestations and rapidly transient lung consolidations, whose daily activities are nevertheless unaffected and who enjoy relatively good health. Reconsideration of the diagnosis is necessary if, owing to relapses, the patient again seeks advice.

Bronchiectatic cases sometimes present difficulty. Before the symptoms have become clinically stable, they may show a somewhat variable and indefinite picture. Sometimes, for instance, they cause lobular atelectasis, which at times clears up very rapidly. (The middle lobe of the right lung appears to be particularly liable to be affected.) Another difficulty is that in these bronchiectatic cases there is often an asthmatic element in the lung symptoms. As has been pointed out previously $(1935,1936)$, this may possibly be ascribed to bacterial allergy due to the infecting organisms present in the dilatations of the bronchi in acute attacks, i.e. sensitive phases. Moderate fever is then met with, usually an increased sedimentation rate and a diffuse bronchitis, which is often localized in both lungs and may be of asthmatic type, accompanied by tightness, wheeziness and murmurs in the chest, signs of emphysema and numerous rhonchi. Some of the symptoms may disappear rapidly, when the 
patient enters the de-sensitive phase. Far and away the best diagnostic aid for the bronchiectatic group is the bronchograph. It may be difficult, however, to determine whether the asthmatic bronchitis is primary or secondary to the bronchiectasis.

\section{Conclusions}

Transient allergic lung consolidation is a well-defined diagnosis in typical cases, but is one which calls for x-ray examination. In complicated cases the diagnosis is substantiated in the first place by the transient nature of the condition (usually a matter of hours). If the condition persists for a matter of days, the diagnosis becomes more and more uncertain. Secondly, it is necessary that the case should show an allergic disposition, either by exhibiting eosinophilia or other allergic manifestations, such as asthma and evidence of hypersensitivity. The absence of eosinophilia in the blood does not necessarily exclude the diagnosis, nor does the presence of pyrexia and disturbance of general health. This is particularly true of the asthmatic types, in which an infection of the upper air passages may give rise to an attack of asthma, which in its turn causes transient consolidations. In the absence of repeated examinations, the transient nature of the consolidation may not be recognized, and in this the practitioner will sometimes have an advantage over the out-patient physician.

The disease is thus not only theoretically interesting, but provides a differential diagnosis which explains a large number of atypical bronchopneumonias and so-called one-day-pneumonias, and even of so-called ' rapidly recovering tuberculous cases' in patients who are tuberculin-positive or suspected of tuberculosis. An acquaintance with transient lung consolidations appears to be of the greatest importance in connexion with the allergic complaints most generally met with, namely asthma and asthmatic bronchitis. These asthmatic conditions are often sent for $\mathrm{x}$-ray examination. The transient shadows in asthmatic children are prone to appear in the form of massive indurations of atelectatic type, probably conditioned by bronchial spasms, with stagnation of secretions. They vary very much in size and localization.

In view of the evidence that has been brought forward, Löffler's definition of 1934 will require some slight modernization. The transience of the consolidation should be more stressed, the eosinophilia in the blood less so. The occurrence of the complaint in asthmatic persons should be emphasized, as also the possibility of a simultaneous infection, which may change the blood picture, the sedimentation reaction and the general condition.

\section{REFERENCES}

Eckerström, S. (1936). Hygiea, Stockh., 98, 198.

Engel, D. (1935). Beitr. klin. Tuberk., 87, 239.

Leitner, J. (1936). Ibid., 88, 388.

Löfller, W. (1932). Ibid., 79, 368.

- (1934). (See Engel.)

Söderling, B. (1935). Acta paediatr., Stockh., 17, 528.

- (1936). Nord med. Tidskr. 12, 1868. 